\title{
Medicare finances: a review
}

\author{
Gilbert Berdine MD
}

Much can be learned about Medicare finances from the annual report from the trustees. ${ }^{1}$ Data about Medicare revenues and expenses from the past and present as well as projections of the future can be found in this document

In 2014 Medicare had 53.8 million beneficiaries. The beneficiaries were 44.9 million people aged 65 or older and 8.9 million people classified as disabled. Expenditures were $\$ 613.3$ billion for an average benefit of $\$ 11,399.63$. Income from payroll taxes was
$\$ 599.3$ billion. So-called interest income from the socalled Trust Fund was $\$ 11.2$ billion. I say "so-called" because the money in the Trust Fund was, in fact, already spent by Congress in the past. The "Trust Fund" exists as IOUs that Congress "promises" to pay back with future taxes. The so-called interest income is an accounting gimmick of Congress adding to what they "promise" to pay back in the future. Despite these solemn promises, the trustees project that by 2030 the so-called Trust Fund will be depleted and even the pretense of solvency will evaporate.

\section{Figure 1}

\begin{tabular}{|c|c|c|c|c|}
\hline & \multirow[b]{2}{*}{$\mathrm{HI}$ or Part A } & \multicolumn{2}{|c|}{ SMII } & \multirow[b]{2}{*}{ Total } \\
\hline & & Part B & Part D & \\
\hline Assets at end of 2013 (billions) & $\$ 205.4$ & $\$ 74.1$ & $\$ 1.0$ & $\$ 280.5$ \\
\hline Total income & $\$ 261.2$ & $\$ 259.8$ & $\$ 78.2$ & $\$ 599.3$ \\
\hline Payroll taxes & 227.4 & - & - & 227.4 \\
\hline Interest & 8.8 & 2.4 & 0.0 & 11.2 \\
\hline Taxation of benefits & 18.1 & - & - & 18.1 \\
\hline Premiums & 3.3 & 65.6 & 11.4 & 80.3 \\
\hline General revenue & 2.0 & 188.5 & 58.1 & 248.6 \\
\hline Transfers from States & - & - & 8.7 & 87 \\
\hline Other & 1.6 & 3.3 & - & 5.0 \\
\hline Total expenditures & $\$ 269.3$ & $\$ 265.9$ & $\$ 78.1$ & $\$ 613.3$ \\
\hline Benefits & 264.9 & 261.9 & 77.7 & 604.5 \\
\hline Hospital & 139.2 & 44.1 & - & 183.3 \\
\hline Skilled nursing facility & 28.8 & - & - & 28.8 \\
\hline Home health care & 6.6 & 11.2 & - & 17.8 \\
\hline Physician fee schedule services & - & 69.2 & - & 69.2 \\
\hline Private health plans (Part C) & 74.0 & 85.7 & - & 159.7 \\
\hline Prescription drugs & - & - & 77.7 & 77.7 \\
\hline Other & 16.3 & 51.7 & - & 68.0 \\
\hline Administrative expenses & $\$ 4.5$ & $\$ 4.0$ & $\$ 0.4$ & $\$ 8.8$ \\
\hline Net change in assets & $-\$ 8.1$ & $-\$ 6.1$ & $\$ 0.1$ & $-\$ 14.1$ \\
\hline Assets at end of 2014 & $\$ 197.3$ & $\$ 68.1$ & $\$ 1.1$ & $\$ 266.4$ \\
\hline \multicolumn{5}{|l|}{ Enrollment (millions) } \\
\hline Aged & 44.6 & 41.3 & n/a & 44.9 \\
\hline Disabled & 8.9 & 8.1 & n/a & 8.9 \\
\hline Total & 53.5 & 49.3 & 40.5 & 53.8 \\
\hline Average benefit per enrollee & $\$ 4,951$ & $\$ 5,308$ & $\$ 1,920$ & $\$ 12,179$ \\
\hline
\end{tabular}

Corresponding author: Gilbert Berdine MD

Contact Information: Gilbert.Berdine@ttuhsc.edu DOI: $10.12746 /$ swrccc 2016.0414 .185 
Figure 1 is the summary data for calendar year 2014. Medicare was originally considered an insurance program, but it has always been a health care subsidy from working young people to the elderly and disabled. When Medicare critics claim that Medicare is a Ponzi scheme, its supporters claim that it is pay as you go, but a careful exam of Figure 1 reveals this claim to be inaccurate. Part A is the Hospital Insurance $(\mathrm{HI})$ program and it comes closest to being pay as you go. Payroll taxes of $\$ 227.4$ billion failed to cover expenses of $\$ 269.3$ billion. The accounting gimmicks to make income appear larger are relatively small for Part A compared to the other Medicare programs, but even including all of the gimmicks as income, there was an \$8.1 billion deficit to Part A in 2014.
Part $B$ is the program for outpatient and physician payments and Part $D$ is the prescription drug benefit. Payroll taxes do not apply to these programs. These programs are largely funded by General Revenue which is the revenue side of a general budget that is perennially in deficit by around $\$ 1$ trillion each year. General revenue supplied a total of $\$ 248.6$ billion to Medicare in 2014, so the true deficit in Medicare was not $\$ 14.1$ billion but $\$ 14.1$ billion plus $\$ 248.6$ billion or $\$ 262.7$ billion. That is a deficit that cannot possibly be closed by any minor tweak and is, in part, why the trustees recommend a $1 / 3$ across the board reimbursement cut every year that Congress rescinds at the 11th hour.

Figure 2

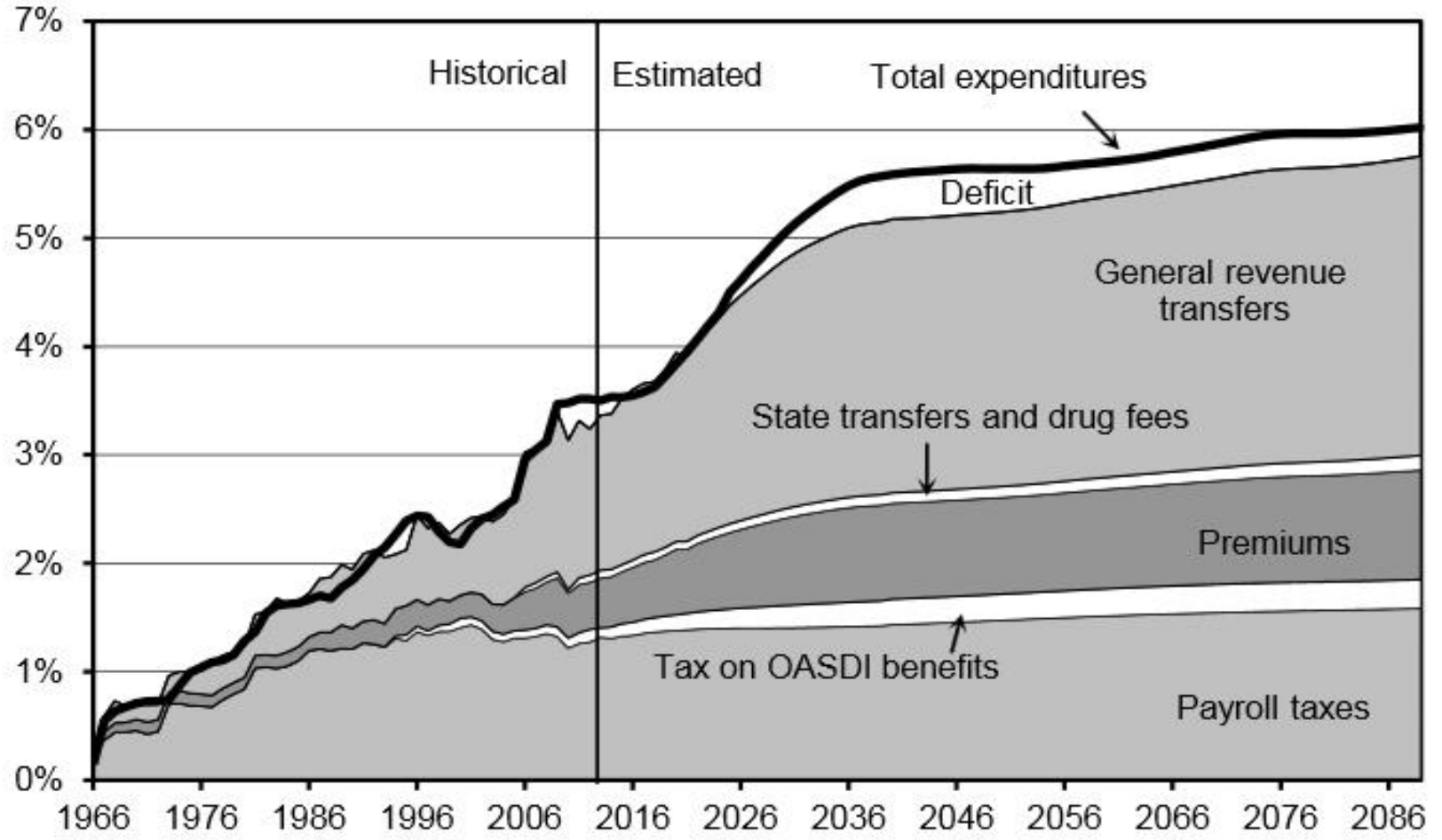

Calendar year

Figure 2 illustrates the past, present and future of Medicare expenses and income as a percent of Gross Domestic Product (GDP). The historic trend is clear: expenses are increasing in a fairly linear manner. Note that the portion of Medicare expenses funded by General Revenue is also increasing over time.
Note that the contribution of payroll taxes has already reached a plateau. This is because it is widely expected that further increases in payroll tax rates would either be rejected by the public or actually reduce revenue due to outsourcing of labor to other countries. 
By expressing expenses as a percent of GDP, one eliminates the effects of increasing population, price inflation, and the ability to pay more due to greater wealth. The percent graphed in Figure 2 can be considered as a measure of the affordability of
Medicare. Higher numbers are less affordable. Note that total expenditures reach a much slower rising plateau around 2036. This is due to future capping of physician reimbursement by current law. We will return to this issue later in the discussion.

Figure 3

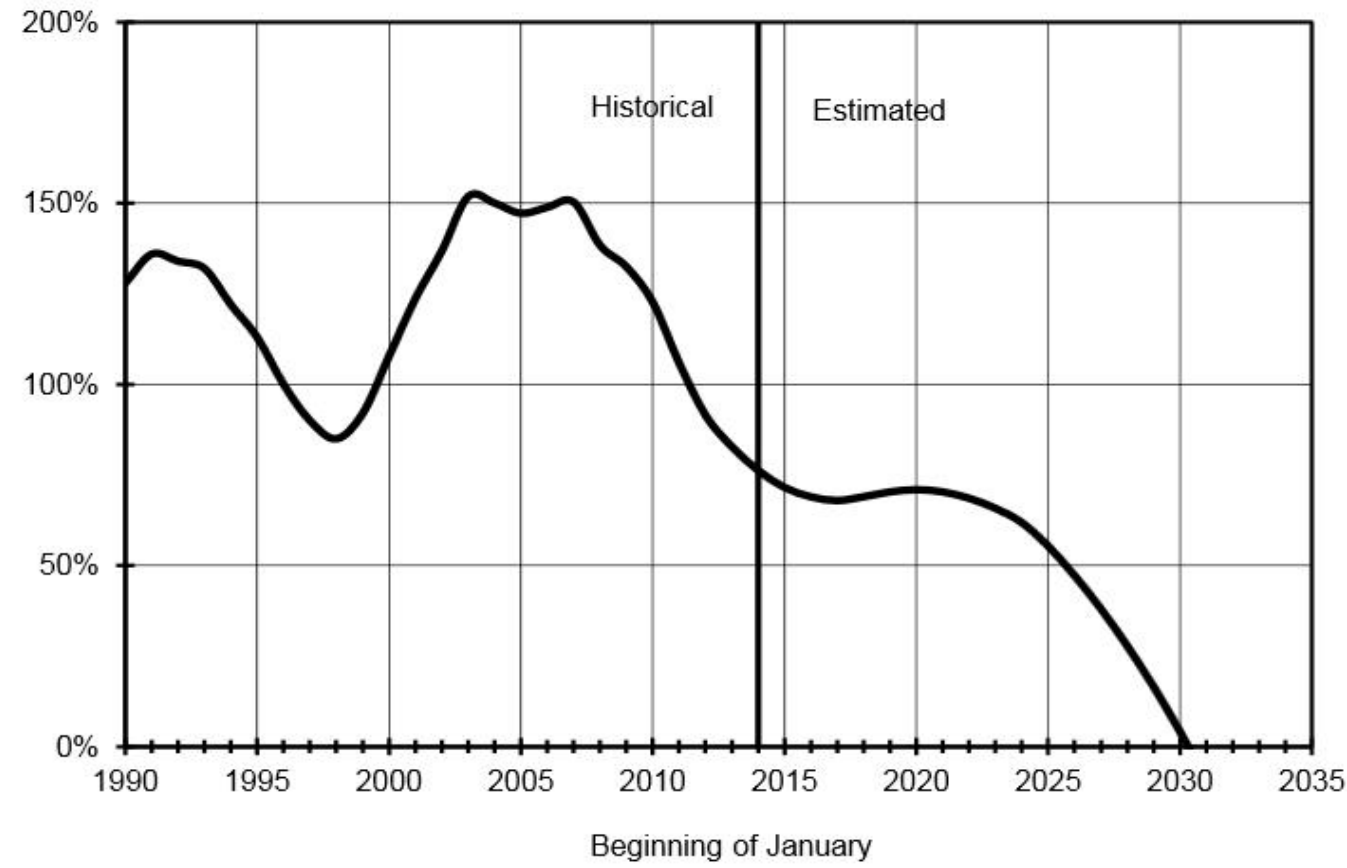

Figure 3 illustrates the Part A Trust Fund each January as a percentage of annual expenditures. This scales the trust fund to the size of the cash flow. It would be comparable to expressing one's bank account as the number of years of average expenditures. One can see from Figure 2 that any talk of stabilizing Medicare will be short lived and that the accounting gimmick loses all pretense of representing something "saved" in 2030.

The above discussion is the current account and does not include what actuaries call the unfunded liability of Medicare. The unfunded liability looks at the projections of income and expenses out to the infinite horizon and considers what amount would have to be added to the system in order to make the system solvent from here on out. The estimates of this unfunded liability vary based on projections, but they range from around $\$ 20$ trillion to $\$ 200$ trillion. The smallest estimate is large even by U.S. government standards.

Figure 4 illustrates current and projected Medicare expenditure as a percent of GDP. As discussed above, this percentage has been increasing steadily since Medicare was created in 1965 . The break in the trend at 2025 to a very slowly increasing plateau around 2035 is due to legislative changes that have been enacted. One of the major changes is contained within the Medicare Access and CHIP Reauthorization Act of 2015 (MACRA). ${ }^{2}$ As the trustees interpret the law, "Under MACRA, a significant one-time payment reduction is scheduled for most physicians in 2025. In addition, the law specifies physician payment rate updates of 0.75 percent or 0.25 percent annually thereafter. These updates are notably lower than the projected physician cost increases, which are assumed to average 2.3 percent per year in the long range." 1 The alternative (dashed) projection 
Figure 4

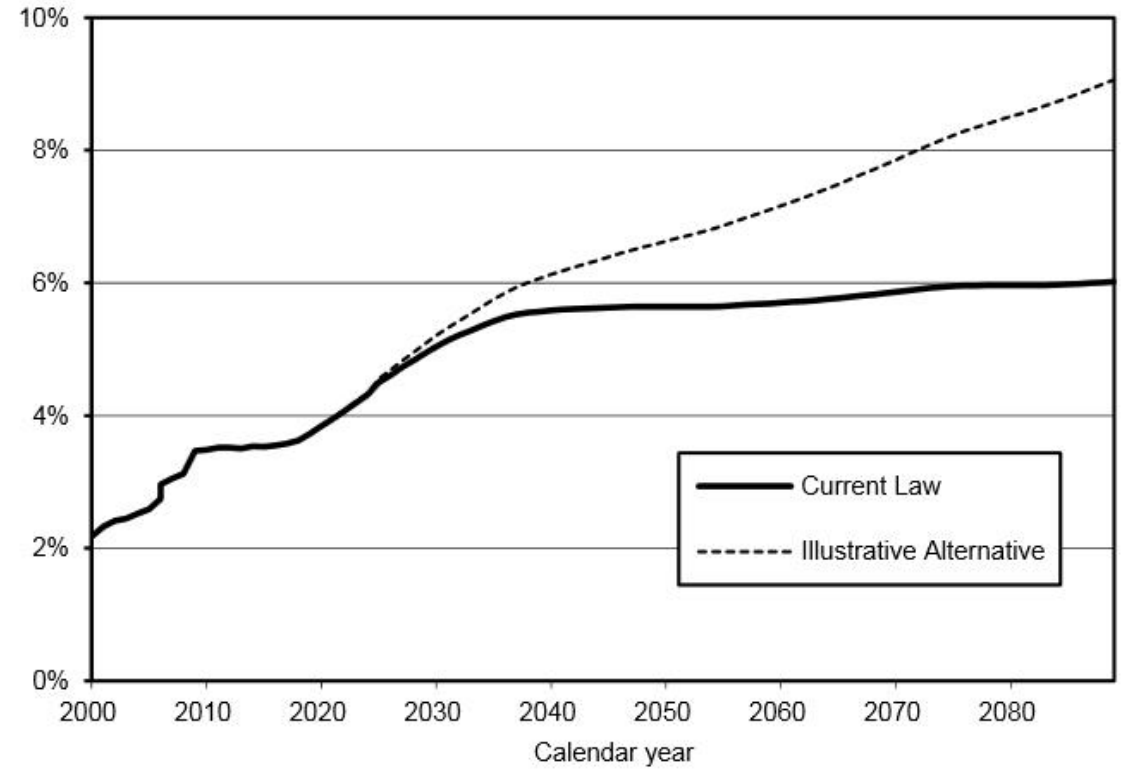

assumes that the cost containment will be rescinded much as the annual recommendation for a $1 / 3$ across the board cut has been rescinded every year. At some point, physicians will see their reimbursement decline either in a transparent across the board manner or disguised as pay for performance where some percentile of physicians are penalized regardless of absolute performance. Elsewhere in the report, the trustees offer this sober assessment of the legislated reimbursement caps: "Without fundamental change in the current delivery system, these adjustments would probably not be viable indefinitely."1

There are many factors driving the increase in Medicare expenditures, but the most problematic factor is the changing demographics of the U.S. population.

Figure 5

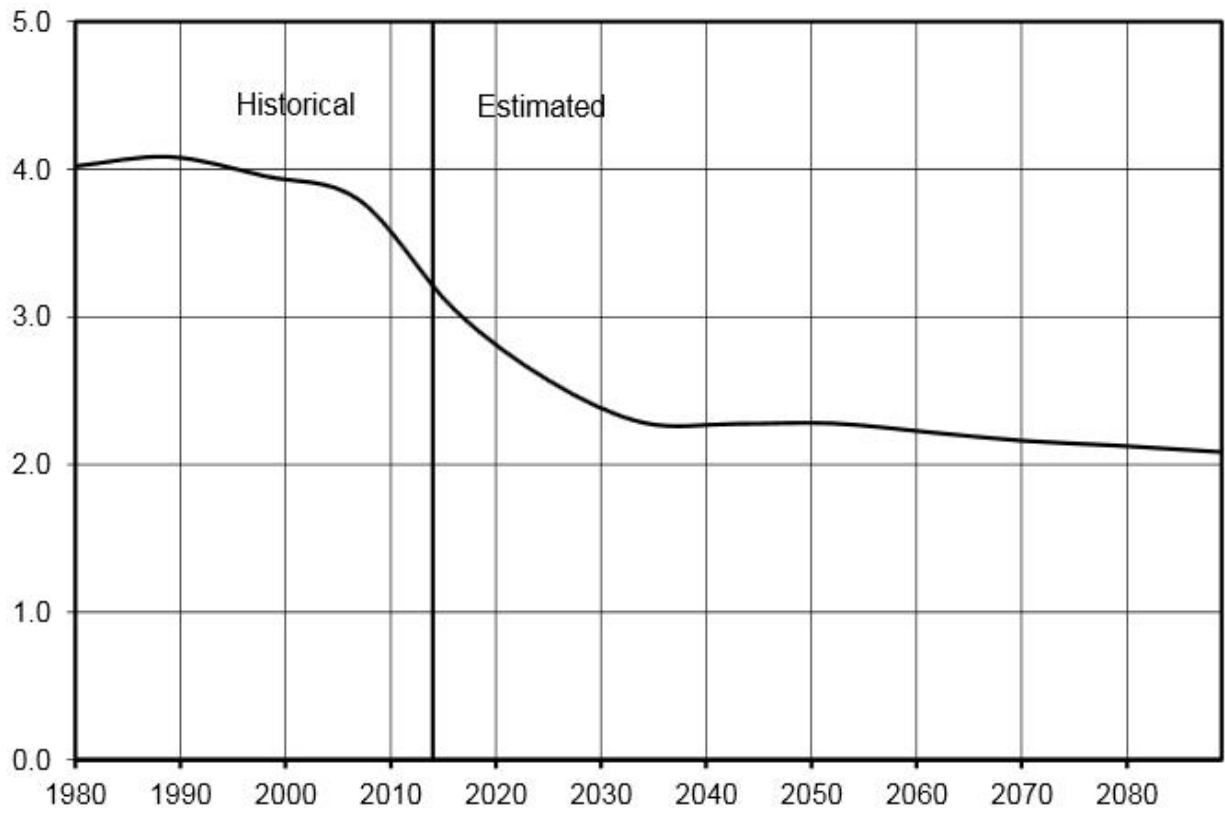

Calendar Year 
Figure 5 illustrates the declining ratio of number of workers per Medicare beneficiary. The decrease that we are currently within is largely due to the retirement of the baby boomer generation. These demographic trends are beyond the control of Congress. The projected trends in Medicare expenditures cannot be wished away by some political gimmick and will require a radical restructuring of Medicare. Given the hard facts, we will either need to decrease benefits to beneficiaries, decrease reimbursement to providers, increase taxes on workers, import large amounts of foreign labor, or some combination of these choices. Politically, all of the choices are unpalatable which explains why politicians want to pretend that there is no problem.

\section{Figure 6}

\begin{tabular}{|c|c|c|c|}
\hline & Intermediate & Low-Cost & High-Cost \\
\hline \multicolumn{4}{|l|}{ Economic: } \\
\hline \multicolumn{4}{|l|}{ Annual percentage change in: } \\
\hline Gross Domestic Product (GDP) per capita ${ }^{1}$ & 4.0 & 5.2 & 2.7 \\
\hline Average wage in covered employment ..................... & 3.9 & 5.2 & 2.6 \\
\hline Private nonfarm business multifactor productivity ${ }^{2} \ldots$ & 1.1 & - & - \\
\hline Consumer Price Index (CPI) & 2.7 & 3.4 & 2.0 \\
\hline Real-wage differential (percent) & 1.2 & 1.8 & 0.6 \\
\hline Real interest rate (percent) & 2.9 & 3.4 & 2.4 \\
\hline \multicolumn{4}{|l|}{ Demographic: } \\
\hline Total fertility rate (children per woman) .............. & 2.00 & 2.20 & 1.80 \\
\hline Average annual percentage reduction in total & & & \\
\hline age-sex adjusted death rates from 2039 to 2089 . & 0.71 & 0.40 & 1.02 \\
\hline Net annual immigration & $1,155,000$ & $1,465,000$ & 850,000 \\
\hline \multicolumn{4}{|l|}{ Health cost growth: } \\
\hline \multicolumn{4}{|l|}{ Annual percentage change in per beneficiary } \\
\hline \multicolumn{4}{|l|}{$\begin{array}{l}\text { Medicare expenditures (excluding demographic } \\
\text { impacts) }\end{array}$} \\
\hline HI (Part A) & $3.8^{3}$ & 4 & 4 \\
\hline SMI Part B & $3.8^{3}$ & 4 & 4 \\
\hline SMI Part D ......... & $4.7^{3}$ & 4 & 4 \\
\hline Total Medicare.... & $4.0^{3}$ & 4 & 4 \\
\hline
\end{tabular}

Figure 6 contains the economic assumption of the trustees. It is clear from these assumptions that expenditures may very well increase faster than projected. The assumptions for economic growth seem wildly optimistic. Assumptions for immigration are problematic. More immigrants mean more workers, but also mean more people on Medicaid under ACA. It will not help to shore up Medicare by transferring costs to Medicaid. Politicians like to promise goodies now that will be paid for in the future, but this analysis shows that the bill for past promises is coming due a lot sooner than most people expected. 
Author Affiliation: Dr. Gilbert Berdine is a pulmonary physician in the Department of Internal Medicine, TTUHSC.

Received: $2 / 14 / 2016$

Accepted: 4/6/2016

Published electronically: 4/15/2016

\section{References}

1.https://www.cms.gov/research-statistics-data-and-systems/statistics-trends-and-reports/reportstrustfunds/downloads/tr2015.

pdf

2.https://www.congress.gov/bill/114th-congress/house-bill/2/

text 